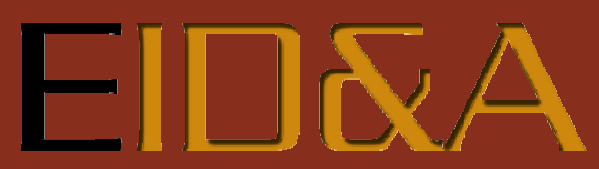

Revista Eletrônica de Estudos Integrados em Discurso e Argumentação

http://dx.doi.org/10.17648/eidea-15-1959

\title{
A AMEAÇA COMO ÚLTIMO RECURSO ARGUMENTATIVO EM AUDIÊNCIAS DE CONCILIAÇÃO NO PROCON
}

\author{
Amitza Torres Vieira ${ }^{i}$ \\ Rogéria Tarocco dos Santos ${ }^{\text {ii }}$
}

Resumo: $O$ presente trabalho tem como objetivo analisar as ameaças produzidas no PROCON. Nesse contexto, o fato de o reclamante e o reclamado apresentarem posições diferentes acerca da reclamação gera um embate de ideias no qual cada participante busca sustentar seu ponto de vista por meio de argumentos. Com base no modelo interacional de argumentação proposto por Schiffrin (1987) e nos movimentos argumentativos encontrados por Barletta (2014), este estudo buscou averiguar se, no PROCON, as ameaças são utilizadas como estratégias argumentativas. A análise do presente estudo é de natureza qualitativa e interpretativa (DENZIN e LINCOLN, 2000), com base em dados reais de fala, transcritos segundo as convenções do modelo Jefferson (1974). Os resultados mostram que, quando cada parte sustenta seu ponto de vista e não se mostra disposta à formulação do acordo, a ameaça pode ser utilizada como último recurso argumentativo a fim de estabelecer a resolução do conflito.

Palavras-chave: Ameaça. Argumentação. Situação de Conflito. Audiência de Conciliação.

Abstract: The present work aims to analyze the threats produced in PROCON. In this context, the fact that the complainant and the defendant present different positions on the complaint generates a clash of ideas in which each participant tries to support his point of view by means of arguments. Based on the argumentation model proposed by Schiffrin (1987) and in the argumentative movements found by Barletta (2014), this study sought to determine if, in PROCON, the threats are used as argumentative strategies. The analysis of the present study is qualitative and interpretive (DENZIN and LINCOLN, 2000), based on real speech data, transcribed according to the Jefferson (1974) conventions. The results show that when each party sustains its point of view and is not willing to formulate the agreement, threats can be used as a last resort to settle the conflict.

Keywords: Threat. Argumentation. Conflict Situation. Conciliation Hearing.

\footnotetext{
i Professora Adjunta da Universidade Federal de Juiz de Fora (UFJF), Brasil. E-mail: amitzatv@yahoo.com.br.

ii Doutoranda Universidade Federal de Juiz de Fora (UFJF), Brasil. E-mail: rocatarocco@gmail.com.
} 
EID\&A - Revista Eletrônica de Estudos Integrados em Discurso e Argumentação, llhéus, n. 15, jan./jun.2018.

\section{Introdução}

Este artigo tem como objeto de estudo a argumentação no contexto institucional de audiências de conciliação do PROCON. A interação promovida pelo órgão de defesa do consumidor funciona como um fórum popular no qual as partes envolvidas advogam em causa própria. As audiências são conduzidas por um mediador (representante do PROCON) com o intuito de promover acordo entre reclamante (consumidor) e reclamado (fornecedor de bens e serviços).

Os participantes - reclamante e reclamado - dirigem-se ao órgão devido a um conflito de interesses, e a busca por um acordo requer negociações nas quais as partes apresentam argumentos que visam à sustentação do ponto de vista defendido por cada uma delas. Como o êxito desses encontros está atrelado às habilidades persuasivas das partes, os participantes fazem uso de movimentos argumentativos para conseguir a adesão ao ponto de vista defendido. Nos movimentos previstos por Barletta (2014), no entanto, não é descrita a ação de ameaçar. Como tal ação, em algumas audiências, estava atrelada à resolução do conflito, buscamos investigar se a ameaça atua, no PROCON, como estratégia argumentativa e como os participantes coconstroem essas ameaças de modo que elas sejam aceitas ou não como argumentos.

Para este estudo, selecionamos uma audiência - Ok Veículos pertencente ao acervo do Projeto "O papel da avaliação na argumentação em situações de conflito" desenvolvido na Universidade Federal de Juiz de Fora. Realizamos um estudo exploratório de caso de base qualitativa e interpretativa (DENZIN e LINCOLN, 2005), a partir de dados reais de fala-eminteração.

\section{Argumentação e interação}

A tradição dos estudos sobre argumentação remonta a Aristóteles e à sua definição de raciocínio como "um argumento em que, estabelecidas certas coisas, outras coisas diferentes se deduzem necessariamente das primeiras." (ARISTÓTELES, 1978, p. 5). Para o pensador grego, a argumentação está atrelada a uma forma lógica básica, na qual estão presentes premissas das quais se extrai uma conclusão, conhecida como modelo silogístico. 
EID\&A - Revista Eletrônica de Estudos Integrados em Discurso e Argumentação, Ilhéus, n. 15, jan./jun.2018.

Os estudos linguísticos contemporâneos ampliam as noções aristotélicas e propõem a análise de argumentos a partir de dados empíricos (falados ou escritos). Por exemplo, a teoria Pragma-Dialética (VAN EEMEREN e GROOTENDORST, 1984; VAN EEMEREN, 1992) apoia-se na Teoria dos Atos de Fala (AUSTIN, 1962; SEARLE, 1981) para analisar divergência de opinião.

Numa perspectiva interacional (SCHIFFRIN, 1987), a argumentação é coconstruída na interação, e o desenho sequencial da fala argumentativa pode mostrar como os participantes usam a fala para atingir seus objetivos comunicativos em situações reais. A argumentação, para a autora, apresenta três componentes: posição, disputa e sustentação. A posição tem como ponto chave a ideia (isto é, as informações descritivas de situações, estados, eventos e ações no mundo) com a qual o falante se compromete ${ }^{1}$. A disputa refere-se a um desacordo em relação à posição ou à sustentação do oponente. Já a sustentação pode se manifestar de formas diversas desde uma explicação de uma ideia até a justificação de um compromisso.

Outro estudo numa perspectiva interacional é o trabalho de Gille (2001), que investiga a argumentação em diálogos espontâneos entre espanhóis e suecos. Para o autor, toda argumentação é realizada por meio de movimentos argumentativos (doravante, MA), definidos como "o ato de assumir, mediante o dito, uma postura em relação a uma opinião"2 (GILLE, 2001, p. 52). Na abordagem desenvolvida, identificam-se categorias de MAs na fala argumentativa dos participantes, a saber: OPIN (opinião inicial), OPAS (opinião associada), OPRE (opinião que resume, repete ou renova uma sequência argumentativa anterior), ACEI (aceitação), RECH (rechaço), APOI (apoio) e REFU (refutação).

Mais recentemente, pesquisas desenvolvidas por Vieira $(2003,2007)^{3}$ se orientaram pelas postulações de Schiffrin (1987) e Gille (2001) no intuito de investigar argumentação e interação em contextos institucionais. O trabalho de 2003 propõe um modelo potencial de argumentação que, juntamente com

\footnotetext{
${ }^{1}$ Schiffrin (1987) considera que o compromisso pode ser compreendido como uma reivindicação da verdade da proposição, por meio da qual os falantes indicam sua confiança na ideia que estão defendendo. O compromisso será tratado no presente trabalho como o grau de adesão ou alinhamento (GOFFMAN, 1981) que o falante assume em relação a uma posição.

${ }^{2}$ Para o presente trabalho, compreendemos a postura como o compromisso (SCHIFFRIN, 1987) ou alinhamento (GOFFMAN, 1981) do falante em relação a uma posição.

${ }^{3}$ O modelo argumentativo de Vieira (2003) foi elaborado a partir de uma entrevista realizada no Programa Roda Viva, veiculado pela TV Cultura em abril de 2000. Já Vieira (2007) analisa sequências argumentativas na fala de funcionários de uma empresa brasileira do ramo de energia, em entrevistas de consultoria realizadas para avaliar a comunicação na organização.
} 
EID\&A - Revista Eletrônica de Estudos Integrados em Discurso e Argumentação, llhéus, n. 15, jan./jun.2018.

o modelo argumentativo proposto em 2007, vem sendo utilizado como ferramenta de análise empírica em diferentes contextos ${ }^{4}$. Os modelos argumentativos propostos por Vieira $(2003,2007)$ são potenciais, isto é, eles não se apresentam como concluídos, mas são passíveis de serem ampliados com novos MAs ou podem sofrer restrições à ocorrência de determinados MAs, de acordo com a situação de fala que é investigada. Apesar da necessidade de adaptação ao contexto, sua aplicabilidade pode se dar também em atividades de fala em que há algum tipo de ordenamento legal a caracterizar os argumentos, tal como em situações de conflito institucional.

A partir dessa abordagem teórico-metodológica, Barletta (2014) identifica MAs em audiências de conciliação no PROCON e propõe o seguinte modelo potencial nesse contexto institucional.

\section{Quadro 1 - Modelo de Barletta (2014) para a argumentação no PROCON}

\begin{tabular}{|c|c|}
\hline $\begin{array}{ll}\text { COMPONENTES } & \text { DA } \\
\text { ARGUMENTAÇÃO } & \end{array}$ & $\begin{array}{l}\text { MOVIMENTOS } \\
\text { ARGUMENTATIVOS (MAS) }\end{array}$ \\
\hline Posição & $\begin{array}{l}\text { POSIN } \\
\text { POSAS } \\
\text { POSRE }\end{array} \quad$ AVA $\}$ \\
\hline Disputa & $\begin{array}{ll}\text { RECH } \\
\text { REFU }\end{array} \quad$ AVAL \\
\hline Sustentação & $\begin{array}{l}\text { ACEI } \\
\text { Justificação } \\
\text { Evidência Exemplo } \\
\text { Testemunho } \\
\text { Dados } \\
\text { Evidência formal } \\
\quad \text { Fato } \\
\text { Evidência legal } \\
\text { Argumento de autoridade } \\
\text { Senso comum } \\
\text { AVAL }\end{array}$ \\
\hline
\end{tabular}

Fonte: Extraído de Barletta (2014, p. 89)

A posição está associada ao compromisso de um falante a uma ideia. Em audiências de conciliação do PROCON, Barletta (2014) identifica três tipos de

\footnotetext{
${ }^{4}$ Os modelos de Vieira $(2003,2007)$ foram utilizados como base analítica para pesquisas em dados de fala (DIAS e VIEIRA, 2008), em textos escritos (CAPELLANI, 2010; DIAS e VIEIRA, 2012) e em corpora de Ensino a Distância (MENEGUELLI, 2012).
} 
EID\&A - Revista Eletrônica de Estudos Integrados em Discurso e Argumentação, llhéus, n. 15, jan./jun.2018.

posição, a saber: POSIN (posição inicial), POSAS (posição associada) e POSRE (posição repetida). A posição inicial (POSIN) é definida, pela autora, como um movimento argumentativo que introduz a posição do participante em relação ao problema que originou o conflito. Quando uma posição é relacionada à inicial, tem-se uma posição associada (POSAS), e quando há reafirmação ou retomada dessa posição, tem-se uma posição repetida (POSRE).

A disputa é o momento em que os participantes mostram o desacordo com as posições e/ou com as sustentações. Esse componente pode ser expresso pelo rechaço (RECH), quando uma posição contrária é apresentada sem o acréscimo de elementos que sustentem a oposição; ou pela refutação (REFUT), quando são acrescidos argumentos para legitimar a oposição estabelecida.

O terceiro componente da argumentação, a sustentação, é muito recorrente no PROCON, visto que é necessário persuadir a parte contrária da posição defendida. Há diferentes tipos de sustentação, a saber: justificação (movimento de sustentar uma posição com o uso - explícito ou implícito - do conectivo de explicação "porque"); evidência (movimento de sustentar uma posição com exemplos, testemunhos, dados, fatos, evidência legal ${ }^{5}$, etc.); e avaliação (movimento de avaliar uma posição ou uma sustentação). Também o aceite (ACEI) - movimento de aceitação - é considerado um movimento argumentativo de sustentação. Como o estudo de Barletta (2014) foi desenvolvido no mesmo contexto de pesquisa em que realizamos nossas investigações, escolhemos trabalhar como os movimentos propostos pela autora na análise da argumentação de nossos dados.

\section{A ameaça em estudos linguísticos}

Em uma pesquisa na literatura linguística sobre ameaças, identificamos o trabalho de Salgueiro (2010), que caracteriza a ameaça como um ato de fala que compartilha traços diretivos e comissivos ${ }^{6}$. Embora a Teoria dos Atos de Fala não fundamente este estudo, julgamos pertinentes as observações postuladas pelo autor sobre a ameaça.

\footnotetext{
${ }^{5} \mathrm{~A}$ evidência legal corresponde à inserção de argumentos que sustentem o ponto de vista de um participante por meio de evidências, cujo respaldo se encontra na lei, seja com amparo no Código de Defesa do Consumidor (CDC), seja com base em outros documentos legais brasileiros.

${ }^{6}$ De acordo com Searle (1995 [1979]), diretivos são obrigações impostas ao outro, enquanto comissivos são obrigações assumidas para si.
} 
EID\&A - Revista Eletrônica de Estudos Integrados em Discurso e Argumentação, llhéus, n. 15, jan./jun.2018.

Segundo Salgueiro (2010), uma ameaça pode ocorrer mesmo que o ameaçado nada tenha feito para merecê-la, apenas como demonstração de poder. Em casos de vingança, a ameaça se constitui uma forma de fazer aquele que a recebe sofrer por antecipação.

A forma básica de produzir uma ameaça é chamada por Salgueiro (2010) de ameaça elementar, que inclui expressões do tipo: "Você vai me pagar", "Eu vou te matar" ou "Eu vou comer o seu fígado". Nesse tipo de ameaça, o falante se compromete a fazer uma ação prejudicial ao ouvinte.

Além desse tipo, Salgueiro (2010, p. 217) postula também ameaças de natureza condicional, tal como: "Se eles me fizerem chefe do departamento, farei sua vida impossível”" Cabe destacar que uma ameaça condicional é aquela em que a ação futura está sujeita à satisfação da condição expressa, porém o objetivo não é levar o ouvinte a cumprir tal condição, pois seu cumprimento está fora do poder da pessoa ameaçada.

Ameaças do tipo "Se você não me der o dinheiro, eu atiro"9 são, segundo Salgueiro (2010), equivocadamente classificadas como condicionais. Para o autor, o falante que pronuncia esse tipo de ameaça não pretende realizar a ação danosa, ao contrário, o que deseja é a execução de sua vontade pelo ouvinte. Desse modo, o autor propõe que ameaças, cujo compromisso do falante com a realização da ação futura não esteja sujeito apenas ao cumprimento da condição, mas ao cumprimento desta pelo ouvinte, sejam classificadas como condicionais diretivo-comissivas.

Nas ameaças condicionais diretivo-comissivas, a parte antecedente é a negação da parte diretiva. Por exemplo, em uma ameaça do tipo: "se você não parar de chorar, vou colocá-lo de castigo", a expressão da parte diretiva nega aquilo que se deseja, no caso, "pare de chorar". Como destaca Salgueiro (2010), esse tipo de ameaça anuncia para os ouvintes as consequências de não atender a parte diretiva; no caso, punições. O falante recorre à ameaça, segundo o autor, quando considera que apenas a expressão do desejo não seria suficiente para que a parte diretiva fosse satisfeita. Então, para atingir o objetivo, o falante precisa mostrar as desvantagens da não realização.

\footnotetext{
${ }^{7}$ Exemplo de Salgueiro (2010, p. 216) - l'll have your guts for garters!

${ }^{8}$ Exemplos de Salgueiro (2010, p 217) - "If they make me head of the department, I'll make life impossible for you."

${ }^{9}$ Exemplo de Salgueiro (2010, p. 217) - If you dont't give money, I'll shoot you.
} 
EID\&A - Revista Eletrônica de Estudos Integrados em Discurso e Argumentação, Ilhéus, n. 15, jan./jun.2018.

Em relação ao uso de ameaças em situações de conflito, Salgueiro (2010) destaca que os falantes não precisam suavizar as palavras, podendo até ser benéfico acentuar a seriedade das ameaças, tornando-as mais ou menos explícitas. Dessa forma, em uma disputa, as ameaças podem ser usadas como estratégias para conseguir que seu pedido ou oferta sejam atendidos.

Por fim, Salgueiro (2010) questiona se as ameaças podem gerar obrigações. No caso das ameaças em que estão envolvidos apenas o falante e o ouvinte, a única fonte de obrigação é a necessidade de o falante manter sua credibilidade, o que pode não gerar uma obrigação. Já nas ameaças em que há uma testemunha direta ou indireta - que poderá vir a ser ameaçada futuramente -, o falante vê-se na obrigação de realizar o ato, a fim de manter sua credibilidade.

Desse modo, ameaças podem funcionar como promessas indiretas, uma vez que podem gerar obrigação àquele que proferiu a ameaça.

\section{Metodologia e contexto do estudo}

Nosso método de análise é qualitativo e interpretativo, uma vez que enfatizamos as qualidades de processos e de significados, que não são medidos em termos de quantidade ou frequência, mas sim entendidos no contexto no qual ocorrem (DENZIN; LINCOLN, 2005). Pesquisas dessa natureza utilizam o ambiente como fonte de geração dos dados, sendo o pesquisador o instrumento fundamental, pois é ele quem descreve e busca interpretar o sentido dos fenômenos sob a perspectiva dos participantes.

Em termos de posicionamento epistemológico-científico, realizamos um estudo exploratório (GIL, 1999), utilizando a teoria de argumentação aliada aos estudos linguísticos sobre ameaças.

Trabalhamos com dados do PROCON de uma cidade de médio porte do estado de Minas Gerais. O PROCON é um órgão pautado nas diretrizes do Código de Defesa do Consumidor, de acordo com a Lei $n^{\circ}$ 8.078. Ele é composto por consumidores (reclamantes) e por fornecedores de bens e serviços (reclamados). Suas funções são prestar esclarecimentos sobre problemas relativos a relações de consumo e atuar como conciliador de conflitos quando as partes, entre si, não chegam a um acordo. As audiências são organizadas de modo que cada uma das partes possa apresentar seu ponto de vista. $O$ órgão de defesa do consumidor, juridicamente, não tem 
EID\&A - Revista Eletrônica de Estudos Integrados em Discurso e Argumentação, llhéus, n. 15, jan./jun.2018.

força legal para obrigar as partes a assumir um comprometimento legal, tampouco pode tomar as decisões resolutivas, a não ser encaminhar os casos não resolvidos para os juizados especiais. Dessa forma, o único recurso de que dispõem para a resolução do problema é a linguagem, que funciona como uma importante ferramenta do processo de argumentação.

Em respeito à ética, todos os nomes de pessoas, lugares, instituições ou quaisquer outros nomes que sirvam de identificação foram trocados por nomes fictícios ${ }^{10}$. Os dados foram transcritos de acordo com o modelo Jefferson, da Análise da Conversa (SACKS et al., 1974; GAGO, 2004), na fonte courier new 10, conforme prática da área, cujas convenções encontram-se no Anexo 1.

Escolhemos, para nosso estudo, uma audiência que envolve a venda de um carro usado que apresentara problemas após sua aquisição pelo reclamante, José. Este reivindica participação financeira nos gastos que teve com o veículo, mas o reclamado, Lucas, nega-se a ter qualquer tipo de despesa. Ao ficar ciente de que o reclamado vende carro em um estacionamento e não em uma concessionária autorizada, além de não ter emitido nota fiscal do veículo, a mediadora o pressiona a assumir responsabilidades com os gastos do reclamante. Lucas, então, se compromete com o pagamento de uma peça e em verificar os custos de outra para confirmar ou não seu pagamento também.

\section{Análise de dados}

$\mathrm{Na}$ análise dos dados, primeiramente, apresentaremos as posições defendidas pelos participantes e, em seguida, como as partes sustentam suas teses e as estratégias utilizadas, bem como de que maneira refutam e/ou rechaçam a opinião contrária. Por fim, mostraremos as ameaças da mediadora e analisaremos seu papel na construção do acordo.

Como os movimentos argumentativos podem se prolongar por vários turnos de fala, optamos por apresentá-los na ordem em que aparecem na audiência; entretanto, destacamos apenas os fragmentos nos quais percebemos que os participantes estão construindo suas posições,

\footnotetext{
${ }^{10}$ A pesquisa segue o protocolo vigente de ética em pesquisa em seres humanos, de acordo com a resolução 466/12, do Conselho Nacional de Saúde, e beneficia-se de parecer de aprovação do protocolo de pesquisa por um comitê de ética ( $n^{\circ}$ CAAE: 00620912.0.0000.5147, aprovado em $14 / 12 / 2012)$.
} 
EID\&A - Revista Eletrônica de Estudos Integrados em Discurso e Argumentação, llhéus, n. 15, jan./jun.2018.

sustentações e refutações. Nesse sentido, ocultaremos ${ }^{11}$, salvo exceções, por exemplo, contribuições dos interlocutores, tais como continuadores e pequenas sobreposições, além de outros MAs que não estão sob análise no excerto.

Para efeito de análise, os dados foram formatados em quadros nos quais há quatros colunas: a primeira contém a numeração das linhas; a segunda apresenta o nome fictício do participante; a terceira, a fala do participante; e a quarta, o nome dado ao movimento argumentativo ${ }^{12}$ antecedido por um numeral para fins organizacionais da análise.

$\mathrm{Na}$ audiência Ok Veículos, há duas posições ${ }^{13}$ implicitamente recuperáveis: a do reclamante e a do reclamado. Para o primeiro, as despesas do carro devem ser pagas pelo reclamado; já este defende que não é responsável pelo pagamento. O primeiro a apresentar sua posição é o reclamado, como pode ser percebido no Quadro 1:

Quadro 2 - A construção da posição do reclamado

\begin{tabular}{|c|c|c|c|}
\hline $\begin{array}{l}\text { Li- } \\
\text { nha }\end{array}$ & $\begin{array}{c}\text { Partici- } \\
\text { pante }\end{array}$ & Transcrição da fala & $\begin{array}{c}\text { Movimento } \\
\text { argumenta } \\
\text {-tivo }\end{array}$ \\
\hline $\begin{array}{l}36 \\
37 \\
\end{array}$ & Lucas & $\begin{array}{l}\text { ele esteve na lo:ja, pra comprar um carro.>uma } \\
\text { uno< um ponto seis zero. }\end{array}$ & \\
\hline $\begin{array}{l}40 \\
41 \\
42 \\
43 \\
44 \\
45 \\
\end{array}$ & Lucas & $\begin{array}{l}\text { =comp- (0.8) >olhou a uno, levou a uno no } \\
\text { mecânico. voltou (0.5) dizendo< que a uno tinha um } \\
\text { defeito. (0.5) mandamos arrumar. ele passou o } \\
\text { final de semana com o carro. (1.0) não- não- não } \\
\text { no domingo, [(.)> lá] na na< no sábado (não sei) } \\
\text { na segunda-feira, }\end{array}$ & $\begin{array}{c}1 \text { SUSTEN- } \\
\text { TAÇÃO } \\
\text { NARRATIVA }\end{array}$ \\
\hline \begin{tabular}{|l|l|l}
46 \\
47
\end{tabular} & \begin{tabular}{|l|} 
Lucas \\
Tosé
\end{tabular} & $\begin{array}{l}\text { >ele ligou dizendo que não queria< o carro. } \\
\text { nã [o]. }\end{array}$ & $2 \mathrm{RECH}$ \\
\hline 48 & Lucas & [en] tão tudo $\uparrow$ bem. = & - \\
\hline 49 & José & =tá errado. & $3 \mathrm{RECH}$ \\
\hline $\begin{array}{l}66 \\
67\end{array}$ & Lucas & \begin{tabular}{|l} 
Aí, (0.8) > >ele falou que não<< queria ficar com o \\
carro. aí sele falou assim<, então eu vou escolher
\end{tabular} & \\
\hline
\end{tabular}

${ }^{11}$ Os recortes dos excertos aparecem na ordem em que foram recortados, mas não são, necessariamente, sequenciais. As interações foram suprimidas por um critério analítico que tem como objetivo analisar o movimento argumentativo em destaque. A numeração das linhas fornece ao leitor uma ideia da proporção dos recortes. Optamos pela numeração sequencial a fim de que o leitor perceba que estamos fazendo recortes (que podem ser longos ou curtos) nos excertos.

${ }^{12}$ Nos excertos, há sequências não argumentativas, quando isso ocorre, no lugar do nome do movimento argumentativo, colocamos um traço (-).

${ }^{13}$ Como nossa intenção não é aplicar um modelo argumentativo, não selecionamos trechos de todos os tipos de posição, embora haja ocorrências. 
EID\&A - Revista Eletrônica de Estudos Integrados em Discurso e Argumentação, Ilhéus, n. 15, jan./jun.2018.

\begin{tabular}{|c|c|c|c|}
\hline $\begin{array}{l}68 \\
69 \\
70 \\
71 \\
72 \\
73 \\
74 \\
75 \\
76 \\
77 \\
78 \\
79 \\
80 \\
81 \\
\end{array}$ & & $\begin{array}{l}\text { outro carro. > (então) cế fica à vontade. escolheu } \\
\text { um gol.(.) levou o gol pro mecânico dele. (.) } \\
\text { mecânico reprovou o carro. (.) ele voltou. ai ele } \\
\text { escolheu um monza(0.5) levou o monza no mecânico. } \\
(0.2) \text { o monza tá tudo certo. tá. serve pra você. } \\
\text { serve. ficou com o monza. (1.0) levou o monza. no } \\
\text { dia que: >no- no-< depois no sábado, o monza } \\
\text { apareceu um defeito, quebrou a: um- uma balança } \\
\text { lá. (0.5) ele ainda me ligou, foi mandado arrumar } \\
\text { a balança. agora depois de três meses ou dois } \\
\text { meses que >(tem- que ele me) comprou o carro,< ele } \\
\text { me trouxe essa reclamação, dizendo que tem algumas } \\
\text { coisas- que foram gastas algumas coisas no } \\
\text { (.)carro. }\end{array}$ & $\begin{array}{l}4 \text { SUSTEN- } \\
\text { TAÇÃO } \\
\text { NARRATIVA }\end{array}$ \\
\hline 82 & Lucas & $\begin{array}{l}\text { <agora o que foi gasto no carro, (0.2) eu nem sei } \\
\text { o quê que é. nem vi. }\end{array}$ & $5 \mathrm{PC}$ \\
\hline $\begin{array}{l}85 \\
86 \\
87 \\
\end{array}$ & Lucas & $\begin{array}{l}\text { ele tá alegando ó:leo, filtro- é: ve:la, essas } \\
\text { coisas (.) tem que ser fe:ito (0.2) quem compra um } \\
\text { carro usa:do, }\end{array}$ & 6 SUSTEN- \\
\hline $\begin{array}{l}90 \\
91 \\
92\end{array}$ & Lucas & $\begin{array}{l}\text { [ a] gente fala. >tem que fazer a revisão no } \\
\text { carro.< (.) ele me comprou ciente a essas coisas. } \\
(0.8) . \text { <porque a gente não enganou ele em nada. }\end{array}$ & $\begin{array}{l}\text { FATO } \\
\text { JUSTIFI- } \\
\text { CAÇÃO }\end{array}$ \\
\hline $\begin{array}{l}93 \\
94\end{array}$ & Lucas & $\begin{array}{l}\text { agora. essa reclamação que ele fe::z, (1.5) num } \\
\text { posso- }(0.5)\end{array}$ & $\begin{array}{l}7 \text { POSIN } \\
\text { INTER- } \\
\text { ROMPIDA }\end{array}$ \\
\hline $\begin{array}{l}95 \\
96\end{array}$ & Lucas & $\begin{array}{l}\text { agora a garantia de motor e caixa, a gente é- a } \\
\text { gente:: (.) é obrigado. }\end{array}$ & 8 POSAS \\
\hline
\end{tabular}

No Quadro 1, é possível perceber que Lucas não inicia apresentando sua posição, ele está preocupado primeiro em construir a imagem de comerciante honesto que facultou ao cliente o direito de escolha. Nos MAs 1 e 4, ele faz questão de dizer que não lesou o consumidor. O reclamado constrói uma retrospectiva, por meio de uma narrativa, e já sinaliza que não está disposto a propor nenhum acordo, pois o consumidor pôde levar o veículo em seu mecânico e, quando houve reprovação, ele não se negou a conseguir outro carro para o reclamante. Cabe destacar que, ao final dessa sustentação, o reclamado frisa o tempo decorrido desde a venda do veículo, tentando se descomprometer com o prazo de garantia legal, que é de três meses.

Ao dizer "<agora o que foi gasto no carro, (0.2) eu nem sei o quê que é. nem vi.", no MA 5, o marcador "agora" sinaliza a mudança de movimento para a apresentação da posição. O descaso do reclamado evidencia que, para ele, a reclamação é irrelevante. Dessa forma, implicitamente ressalta que não é responsável por pagar as despesas do carro. Entendemos, assim, que essa 
EID\&A - Revista Eletrônica de Estudos Integrados em Discurso e Argumentação, Ilhéus, n. 15, jan./jun.2018.

elocução constituiu a posição inicial (implícita) do reclamado: a de que não é sua responsabilidade arcar com as despesas do carro.

Ao continuar sustentando seu ponto de vista, no MA 6, Lucas ressalta que os itens alegados (vela, filtro e óleo) devem ser vistoriados por quem compra carro usado, ou seja, esse fato também está orientado para a defesa de sua posição. Nas linhas 90-94, o reclamado legitima a imagem de bom fornecedor, visto ter orientado o cliente para fazer a manutenção do veículo. E termina essa fala com uma justificação "<porque a gente não enganou ele em nada."

No MA 7, convém destacar que Lucas opta por não verbalizar que não pode, nem pagará, como pode ser comprovado pela posição inicial interrompida, seguida de pausa: "agora. essa reclamação que ele fe::z, (1.5) num posso- (0.5)".

Por fim, no MA 8, ao usar novamente o marcador "agora" em: "agora a garantia de motor e caixa, a gente é- a gente:: (.) é obrigado.", o reclamado ainda associa à sua posição uma outra, na qual se responsabiliza por cobrir apenas defeitos no motor ou na caixa de marcha, ponto de vista que também será sustentado ao longo da audiência.

A resposta a Lucas ocorre logo após, ainda na primeira fase da audiência Ok Veículos. O excerto (2), a seguir, mostra como o reclamante, José, refuta a argumentação do reclamado e constrói sua posição.

Quadro 3 - A construção da posição do reclamante

\begin{tabular}{|c|c|c|c|}
\hline $\begin{array}{l}\text { Li- } \\
\text { nha }\end{array}$ & $\begin{array}{l}\text { Partic } \\
\text { ipante }\end{array}$ & Transcrição da fala & $\begin{array}{l}\text { Movimento } \\
\text { argumen- } \\
\text { tativo }\end{array}$ \\
\hline 110 & José & [ele- [ele falou que eu peguei a u:no:, & \multirow{4}{*}{$\begin{array}{c}1 \text { REFU } \\
\text { NARRATIVA }\end{array}$} \\
\hline $\begin{array}{l}113 \\
114 \\
115 \\
116\end{array}$ & José & 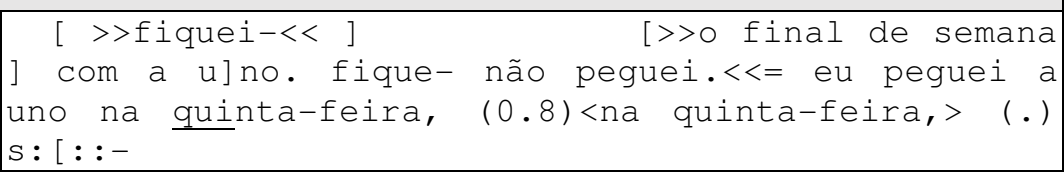 & \\
\hline 118 & José & =no sábado eu voltei lá. & \\
\hline 120 & José & dois dias. & \\
\hline $\begin{array}{l}122 \\
123 \\
\end{array}$ & José & $\begin{array}{l}\text { >daí- eu- eu andei- eu peguei ela na [quinta- } \\
\text { feira] de noite< }\end{array}$ & \begin{tabular}{|c|}
2 REFU \\
NARRATIVA
\end{tabular} \\
\hline 126 & Lucas & [ ( não senhor. $)]$ & $3 \mathrm{RECH}$ \\
\hline
\end{tabular}


EID\&A - Revista Eletrônica de Estudos Integrados em Discurso e Argumentação, Ilhéus, n. 15, jan./jun.2018.

\begin{tabular}{|c|c|c|c|}
\hline $\begin{array}{l}127 \\
128 \\
129\end{array}$ & José & $\begin{array}{l}\text { =(peguei) na quinta-feira de noite. fui trabalhar } \\
\text { sexta nem usei o carro. (1.2) (peguei) na quinta- } \\
\text { feira a noite. sexta nem usei o carro. }\end{array}$ & \multirow{3}{*}{$\begin{array}{c}4 \text { REFU } \\
\text { NARRATIVA }\end{array}$} \\
\hline $\begin{array}{l}132 \\
133 \\
134 \\
\end{array}$ & José & \begin{tabular}{|lllll}
${ }^{\circ}$ certo. ${ }^{\circ}>$ me & me $<$ & venderam & o carro como direção \\
hidráulica, $=>0$ & carro & não tinha & direção \\
hidráulica.< (1.8) & & & & \\
\end{tabular} & \\
\hline $\begin{array}{l}136 \\
137 \\
138 \\
139\end{array}$ & José & $\begin{array}{l}\text { <propaganda enganosa, né.= falar uma coisa que não } \\
\text { tem. (1.2) voltei lá no sábado. (0.8) ah, >o carro } \\
\text { (dá pra ir- (não) apresentava o defeito isso e } \\
\text { aquilo. =voltei. (0.2) }\end{array}$ & \\
\hline $\begin{array}{l}140 \\
141 \\
\end{array}$ & José & $\begin{array}{l}\text { tudo bem } \downarrow \text { conversei levei um gol, (.) >peguei um } \\
g \circ 1,<(.) \text { o mecânico reprovou, }(0.2)\end{array}$ & \multirow{2}{*}{$\begin{array}{c}5 \text { ACEI } \\
\text { NARRATIVA }\end{array}$} \\
\hline $\begin{array}{l}144 \\
145 \\
146 \\
147\end{array}$ & José & $\begin{array}{l}\text { aí peguei um monza, >levei no mecânico, o mecânico } \\
\text { tava bo- olhou o: carro, }<\text { motor é carro usado. } \\
\text { não ia mexer no carro?, (.) olhou o carro tava } \\
\text { bom. (.) certo. }\end{array}$ & \\
\hline $\begin{array}{l}150 \\
151 \\
152 \\
153 \\
154 \\
155 \\
156 \\
157 \\
158 \\
159 \\
160 \\
161 \\
162 \\
163 \\
164 \\
165 \\
166 \\
167 \\
168\end{array}$ & & $\begin{array}{l}\text { =<aí o primeiro dia que eu peguei o monza, peguei } \\
\text { o monza no sábado, (0.8) no sábado (.) o monza já } \\
\text { quebrou a balança não sei o quê que aconteceu lá } \\
\text { que eles (não teve- o defeito no coisa- => no } \\
\text { primeiro dia.<< (.) no tempo (.) do- levei- isso } \\
\text { aconteceu de tarde, }=\text { peguei o monza (.) lá por } \\
\text { volta de dez onze horas da manhã, (0.2) fiquei } \\
\text { trabalha:ndo, depois fui pro lava-a-jato, (1.0) } \\
\text { saí de lá com o carro cinco horas da tarde, parei } \\
\text { o carro na Prudente de Moraes, depois que eu } \\
\text { liguei o carro, (0.5) deu defeito. >acusou o } \\
\text { defeito.= aí na mesma hora ligamos pra ele. (1.0) } \\
\text { "ah não, vê o quê que cês podem fazer aídeixa no } \\
\text { (.) estacionamento que a gente resolve na segunda- } \\
\text { feira".< conseguimos:- arrumar o negócio lá e } \\
\text { levamos no mecânico no sábado mesmo. } \\
\text { =aí o cara deu uma olhada, >tal tal <. (0.5) aí } \\
\text { não suspeitou de nada porque o carro voltou: } \\
\text { (.)ao normal. }\end{array}$ & $\begin{array}{c}6 \text { REFU } \\
\text { NARRATIVA }\end{array}$ \\
\hline 170 & Lucas & não. arrumou a peça. = & 7 REFU \\
\hline 171 & José & $=>>$ não [arrumou - num -$] \quad[$ num arrumou -$]<<$ & $8 \mathrm{RECH}$ \\
\hline $\begin{array}{l}180 \\
181 \\
182 \\
183 \\
184 \\
185 \\
186 \\
187 \\
188 \\
\end{array}$ & José & $\begin{array}{l}\text { ( ) sábado de noite o cara olhou, tirou a roda, } \\
\text { olhou, tal tal. (.) aí (.) demos uma volta no } \\
\text { carro, (.) [aí o cara-] }(1.2) \text { descendo a } \\
\text { Repú: blica, >o cara ( }) \text {. não aconteceu nada. } \\
\text { aí paramos o carro em frente a oficina, a hora que } \\
\text { ele arrancou, o carro voltou a dar problema. aí } \\
\text { deix- ligou pra ele de novo, deixou na oficina aí } \\
\text { na segunda-feira ele mandou arrumar o carro. }\end{array}$ & $\begin{array}{c}9 \text { ACEI } \\
\text { NARRATIVA }\end{array}$ \\
\hline $\begin{array}{l}190 \\
191\end{array}$ & José & $\begin{array}{l}\text { =que foi feito. que foi na segunda-feira que você } \\
\text { foi lá levar a peça= }\end{array}$ & $10 \mathrm{ACEI}$ \\
\hline
\end{tabular}


EID\&A - Revista Eletrônica de Estudos Integrados em Discurso e Argumentação, Ilhéus, n. 15, jan./jun.2018.

\begin{tabular}{|c|c|c|c|}
\hline $\begin{array}{l}193 \\
194 \\
195 \\
196 \\
197 \\
198 \\
199 \\
200 \\
201 \\
202 \\
203 \\
204 \\
205 \\
206 \\
207 \\
208\end{array}$ & José & $\begin{array}{l}\text { =arrumou o carro. (.) tudo bem. aí: (0.8) passou } \\
\text { tudo bem. aí: teve um dia que eu levei o carro pro } \\
\text { esporte, fui jogar bola, o carro me: deixou na mão } \\
\text { lá. não- não ligava >nem pro caramba. (do mesmo } \\
\text { jeito.)< levei logo no: meu mecânico e tá a } \\
\text { notinha aqui. eu tenho que trocar ainda: (0.5) } \\
\text { quatrocentos re- já- fora o que eu gastei eu tenho } \\
\text { que (.) gastar mais quatrocentos e pouco, porque } \\
\text { eu tenho que trocar (1.0) um negócio >que você } \\
\text { sabe< que: desde o primeiro dia que eu peguei } \\
\text { (1.0) tá dando- tá com problema, e tenho que } \\
\text { trocar(.) bomba elétrica. é duzentos e poucos } \\
\text { reais. eu com o carro que eu- tenho dois meses- } \\
\text { paguei a segunda prestação agora, e vou gastar } \\
\text { mais de mil e cem reais no carro. =>num tem } \\
\text { condição. = é três prestações que eu vou pagar.< }\end{array}$ & $\begin{array}{c}11 \text { POSIN } \\
\text { EVIDÊNCIA }\end{array}$ \\
\hline $\begin{array}{l}217 \\
218 \\
\end{array}$ & Marta & 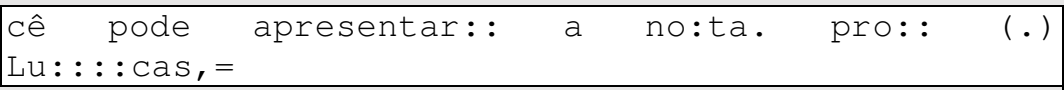 & \multirow[b]{2}{*}{12 POSIN } \\
\hline $\begin{array}{l}220 \\
221 \\
222 \\
223\end{array}$ & Marta & 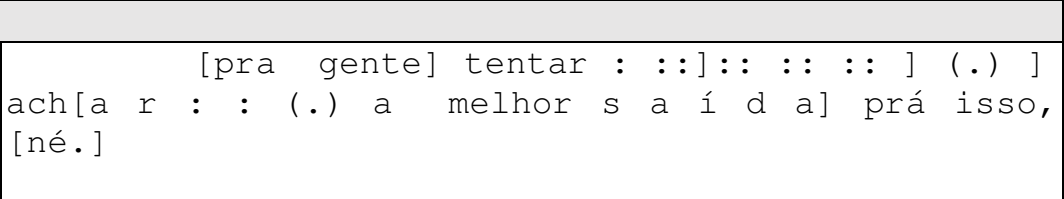 & \\
\hline
\end{tabular}

No Quadro 3, José, inicialmente, refuta o fato de Lucas ter afirmado, nas linhas 42 e 43, que ele havia ficado com o carro durante o fim de semana. Por meio de narrativa, o reclamante justifica o motivo pelo qual rejeitou os carros. Esse MA funciona como resposta à ênfase dada pelo reclamado ao direito que ele teve de escolher. Como o reclamante observa, o primeiro carro foi recusado porque foi feita uma propaganda enganosa: foi oferecido com direção hidráulica, sem a ter. Já o segundo foi reprovado pelo mecânico. O carro escolhido, embora tenha sido aprovado pelo mecânico, apresentou problemas logo após a compra.

No MA 6, José refuta a afirmação feita por Lucas de que o defeito havia aparecido após três meses. A narrativa ilustra que, já no primeiro dia, houve problema, mas reconhece que o vendedor não se negou a repará-lo, como comprovam os MAs 9 e 10.

Entretanto, José alega que o valor gasto, posteriormente, nos reparos equivale a três prestações e, por isso, sua posição inicial (implícita), expressa no MA 11, é a de que o reclamado precisa arcar com os gastos, como podemos perceber no seguinte fragmento: "tá a notinha aqui. eu tenho que trocar ainda: (0.5) quatrocentos re- já- fora o que eu gastei eu tenho que (.) gastar mais quatrocentos e pouco". A "notinha" a que o consumidor se refere 
EID\&A - Revista Eletrônica de Estudos Integrados em Discurso e Argumentação, Ilhéus, n. 15, jan./jun.2018.

funciona como uma evidência do que foi gasto e que precisa de ressarcimento.

Ao final do excerto (2), MA 12, destacamos também a fala da mediadora que ratifica que a nota será usada como comprovação do valor pago pelo consumidor em busca de compensação. Após a apresentação das posições, os participantes utilizam estratégias para sustentar as teses defendidas, como destacaremos nos excertos do Quadro 4.

Quadro 4 - Sustentações do reclamado

\begin{tabular}{|c|c|c|c|}
\hline $\begin{array}{l}\text { Li- } \\
\text { nha }\end{array}$ & $\begin{array}{c}\text { Parti- } \\
\text { cipante }\end{array}$ & Transcrição da fala & $\begin{array}{l}\text { Movimento } \\
\text { argumen- } \\
\text { tativo }\end{array}$ \\
\hline 229 & Marta & [o consumidor] se sent [iu lesa: : ]do= & 1 POSAS \\
\hline $\begin{array}{l}234 \\
235\end{array}$ & Lucas & $\begin{array}{l}={ }^{\circ} \text { se sentiu lesado mas (.) >>a partir do momento- } \\
\text { a gente não enganou ele em nada. }\end{array}$ & 2 REFU \\
\hline $\begin{array}{l}236 \\
237 \\
238\end{array}$ & Lucas & $\begin{array}{l}\text { ele levou } \\
\text { dele- carro no mecânico dele, } 0 \text { mecânico } \\
\text { comprar.< }\end{array}$ & $\begin{array}{l}3 \text { SUSTEN- } \\
\text { TAÇÃO } \\
\text { ARG. DE } \\
\text { AUT. }\end{array}$ \\
\hline $\begin{array}{l}239 \\
240\end{array}$ & Lucas & $\begin{array}{l}\text { porque se o carro tivesse ruim, ele não tinha } \\
\text { comprado o carro. }\end{array}$ & \begin{tabular}{|c|} 
SUSTEN- \\
TAÇÃO \\
JUSTIFICAÇÃO
\end{tabular} \\
\hline $\begin{array}{l}248 \\
249 \\
250 \\
251 \\
\end{array}$ & Lucas & $\begin{array}{l}\text { [oagora, essas coisas que ele }{ }^{\circ} \text { tá: : } \text { aleg- isso } \\
\text { aí é coisa de um carro usado. isso aí é um carro } \\
\text { noventa e quatro. (0.5) (estamos) no ano dois mil. } \\
\text { faz seis anos= }\end{array}$ & $\begin{array}{l}5 \text { SUSTEN- } \\
\text { TAÇÃO } \\
\text { FATO }\end{array}$ \\
\hline $\begin{array}{l}371 \\
372 \\
\end{array}$ & Lucas & $\begin{array}{lllll}{[\text { nã : }]:: \text { : }} & \text { mas } & 0 & \text { motor } & \text { não } \\
\end{array}$ & 6 SUSTEN- \\
\hline 375 & Lucas & =a caixa não estragou: : :- & FATO \\
\hline $\begin{array}{l}393 \\
394 \\
395 \\
396 \\
397 \\
398 \\
399 \\
400 \\
\end{array}$ & Lucas & $\begin{array}{l}\text { otanto (.) que isso aqui > sele tá dizendo<<o, } \\
\text { nu:ma revisão de carro. > que é as coisas que são } \\
\text { gast-. ele levou o carro no mecânico dele, se o } \\
\text { carro não tivesse em condições, ele não teria que } \\
\text { ter comprado. correto? (0.8) o mecânico dele } \\
\text { >falava assim.< "não. esse carro não tem condições } \\
\text { de você comprar". o quê que ele tem que fazer? não } \\
\text { comprar o automóvel. }\end{array}$ & $\begin{array}{l}7 \text { SUSTEN- } \\
\text { TAÇÃO } \\
\text { ARG. DE } \\
\text { AUT. }\end{array}$ \\
\hline $\begin{array}{l}410 \\
411 \\
412 \\
\end{array}$ & Lucas & $\begin{array}{l}\text { [depois] de- (.) trê:: : :s meses, dois meses, } \\
\text { ele vem com essas- (reclamações). isso aí (.) >é } \\
{[\text { coisa]<= }}\end{array}$ & $\begin{array}{l}8 \text { SUSTEN- } \\
\text { TAÇÃO }\end{array}$ \\
\hline 415 & T.1cas & =olle ele tinha olle ter fei $\cdot$ to $($ l l na hora $=$ & NCIA \\
\hline $\begin{array}{l}417 \\
418\end{array}$ & Lucas & $\begin{array}{l}\text { =porque o mecâ::nico, ele sabe (das coisas que } \\
\text { são-) o mecânico é profissional. }\end{array}$ & \begin{tabular}{|c|}
9 SUSTEN- \\
TAÇÃO \\
JUSTIFICAÇÃO
\end{tabular} \\
\hline
\end{tabular}


EID\&A - Revista Eletrônica de Estudos Integrados em Discurso e Argumentação, Ilhéus, n. 15, jan./jun.2018.

Como nessa audiência o reclamado não está, inicialmente, disposto a formular um acordo, os movimentos argumentativos de sustentação tornamse repetitivos, por isso, optamos por reproduzir apenas uma ocorrência de cada uma das estratégias.

Antes de analisar o excerto acima, recuperamos a sequência narrativa excerto (1), linhas 36-37, 40-45, 66-81 - com a qual Lucas inicia a audiência. Ao relatar que o consumidor teve o direito de escolha e não foi negado o conserto do primeiro problema, o reclamado, implicitamente, apresenta o fato de que a manutenção do veículo compete ao dono do carro.

Esse pensamento torna-se mais explícito no MA 5, quando Lucas apresenta o ano do veículo como evidência de que a reclamação não tem fundamento, pois a manutenção é de responsabilidade do proprietário. Esse MA orienta-se para sua posição inicial: a de que não pagará as despesas que o reclamante teve com o carro.

Já no MA 6, o reclamado sustenta sua posição associada, a de que só lhe compete pagar aquilo que está, segundo ele, na garantia (motor e caixa). Como não houve problemas nessas partes, ele não tem nenhuma responsabilidade em relação às despesas do consumidor.

Ao mencionar o mecânico, nos MAs 3 e 7, Lucas apresenta sua sustentação mais forte: argumento de autoridade. Como o especialista era da confiança do cliente e aprovou o carro, isso significa que o veículo estava bom e poderia ser comprado; logo, a reclamação refere-se a peças de desgaste natural e não a um defeito a ser reparado por quem vendeu. $O$ argumento de autoridade é retomado no MA 9 via justificação. Esse MA, por sua vez, é o mesmo de número 4, no qual é apresentada a razão pela qual o carro foi comprado: "porque se o carro tivesse ruim, ele não tinha comprado o carro."

No MA 8, o reclamado retoma a sustentação já apresentada inicialmente, na qual narrava o processo de escolha do reclamante. Ainda nesse trecho, Lucas retoma o tempo que a reclamação demorou para ser feita. Embora não tenha noventa dias, ele faz questão de dizer que tem, o que também o eximiria da posição associada à de que deveria cobrir três meses de garantia de motor e caixa.

Essas sustentações são refutadas pelo reclamante, José, como pode ser observado no Quadro 5: 
EID\&A - Revista Eletrônica de Estudos Integrados em Discurso e Argumentação, Ilhéus, n. 15, jan./jun.2018.

\section{Quadro 5 - Refutações do reclamante}

\begin{tabular}{|c|c|c|c|}
\hline $\begin{array}{l}\text { Li- } \\
\text { nha }\end{array}$ & $\begin{array}{c}\text { Partici } \\
\text { pante }\end{array}$ & Transcrição da fala & $\begin{array}{c}\text { Movimento } \\
\text { argumen- } \\
\text { tativo }\end{array}$ \\
\hline $\begin{array}{l}452 \\
453 \\
454 \\
455 \\
456 \\
457 \\
458 \\
459 \\
460\end{array}$ & José & $\begin{array}{l}\text { é igual- aconteceu isso aqui ó: (0.5) cabo de } \\
\text { ignição. eu tava indo pra universidade, o levar } \\
\text { minha mãe pra passear, = >meu pai, < começou a dá } \\
\text { um: (1.0) uma a sair- uma faísca de- >uma-< tipo } \\
\text { uma corrente no: : (.) aí eu fui- >vê- lig- o } \\
\text { carro< começou a perder a força.é uma peça } \\
\text { elétrica. como que o cara vai adivinhar na hora, } \\
\text { que ia levar o carro ali pra ele ver, que a peça } \\
\text { vai dar defeito. (1.2) ninguém adivinha. }\end{array}$ & $\begin{array}{c}2 \text { REFU } \\
\text { NARRATIVA }\end{array}$ \\
\hline $\begin{array}{l}462 \\
463 \\
464 \\
465\end{array}$ & José & $\begin{array}{l}\text { =é igual:- >se eu- se eu < num mandasse trocar } \\
\text { algumas coisas aqui no carro?, o quê que } \\
\text { aconteceria com o motor. o carro não ia parar. } \\
(1.0) \text { você não te:m- que trocar? }\end{array}$ & $3 \mathrm{RE}$ \\
\hline $\begin{array}{l}515 \\
516 \\
517 \\
518 \\
519\end{array}$ & Lucas & $\begin{array}{l}\text { [isso aí se ele] tivesse: (.) } \\
\text { um mês depois, que ele comprou >esse carro.< ter } \\
\text { ido lá na lo:ja, conversa:do, mas não num } \\
\text { aconteceu nada. agora que tinha que ( } \\
\text { acontecer= }\end{array}$ & $\begin{array}{l}6 \\
\text { SUSTENTAÇ } \\
\text { Ã O } \\
\text { EVIDÊENCIA }\end{array}$ \\
\hline
\end{tabular}

No MA 1, José refuta o argumento de autoridade usado pelo reclamado por meio de uma construção silogística hipotética "se: ela não acusar o defeito $>$ na hora, < tem como- como a pessoa falar que ela tem que ser troca:da.". Desse modo, mesmo o mecânico sendo especialista, ele não poderia prever o defeito. E este existiu, como comprova a narrativa do MA 2.

Já no MA 3, José argumenta que os defeitos estão relacionados à garantia de motor e caixa, defendida por Lucas. Novamente utilizando uma construção hipotética, o reclamante ressalta que, se as peças não tivessem 
EID\&A - Revista Eletrônica de Estudos Integrados em Discurso e Argumentação, llhéus, n. 15, jan./jun.2018.

sido trocadas, o motor teria parado e Lucas teria que arcar com as despesas. $\mathrm{O}$ mesmo movimento, mas com exemplo diferente, repete-se no MA 5.

Em relação à sustentação de Lucas de que o carro era usado e de que, portanto, teria que ser feita a manutenção, José usa o exemplo de outro carro que teve, um Chevette. Embora não tenha o ano do carro, pelo contexto, deduzimos que também se tratava de um veículo usado com o qual o reclamado não teve despesas. Assim, o MA 4 funciona como uma refutação ao argumento de que carros usados sofrem desgaste natural.

Por fim, destacamos a resposta de Lucas à tentativa de acordo da mediadora. Apesar de todos os seus argumentos terem sido desconstruídos pelo reclamante, o reclamado mantém seu posicionamento de não arcar com as despesas. O MA 6 apresenta uma evidência, reforçando o fato de haver passado tempo demais após a compra. Esse MA é relevante para a compreensão da força da ameaça analisada no Quadro 6.

Quadro 6 - Ameaças da mediadora

\begin{tabular}{|c|c|c|c|}
\hline $\begin{array}{l}\text { Li- } \\
\text { nha }\end{array}$ & $\begin{array}{l}\text { Parti } \\
\text { ci- } \\
\text { pante }\end{array}$ & Transcrição da fala & $\begin{array}{l}\text { Movimento } \\
\text { argumen- } \\
\text { tativo }\end{array}$ \\
\hline $\begin{array}{l}547 \\
548 \\
549 \\
550 \\
551\end{array}$ & Marta & $\begin{array}{l}\text { =<dois MESES.> ele: ( ) hum- (1.0) ((entrada da } \\
\text { advogada - Med 2)) ele tá alegando que a: (0.2) } \\
\text { que a garantia cobre o motor e da caixa de } \\
\text { direção. (0.2) que esse >defeito< que foi aqui } \\
\text { apresenta:do, não::. }\end{array}$ & 1 POSAS \\
\hline $\begin{array}{l}563 \\
564 \\
565 \\
566\end{array}$ & Ana & $\begin{array}{l}\text { [noventa dias cobre tudo. não é só] motor e } \\
\text { caixa. noventa dias é garantia legal. não é } \\
\text { garantia que vocês estão dando. é garantia que [ } \\
\text { a LE I dá. (.) tá:? ] }\end{array}$ & $\begin{array}{l}2 \text { REFU } \\
\text { EVIDÊNCIA } \\
\quad \text { LEGAL }\end{array}$ \\
\hline $\begin{array}{l}567 \\
568 \\
569\end{array}$ & Lucas & $\begin{array}{l}\text { [não, mas a garantia que a gente dá] } \\
\text { perante a nota, é a garantia de motor e caixa do } \\
\text { carro.= }\end{array}$ & $\begin{array}{l}3 \text { REFU } \\
\text { POSAS }\end{array}$ \\
\hline $\begin{array}{l}570 \\
571 \\
\end{array}$ & Ana & $\begin{array}{l}\text { =a garantia que vocês podem da:r, é além dos } \\
\text { noventa dias. noventa dias quem dá é a LEI.= }\end{array}$ & \\
\hline $\begin{array}{l}575 \\
576 \\
577 \\
578 \\
579 \\
580 \\
581 \\
582 \\
\end{array}$ & Ana & $\begin{array}{l}\text { [o produ:to já] tem a garantia de noventa dias. } \\
\text { tá? agora essa garantia de noventa dias você não } \\
\text { pode falar é só isso ou só aquilo NÃo. é a } \\
\text { garantia do produto inteiro. é claro que é uma } \\
\text { coisa: (.) sensata. (.) não vai ser uma garantia } \\
\text { de uma coisa:: (.) perfeitamente visível que ele } \\
\text { poderia- igual eu acredito que é o carro usado que } \\
\text { ele levou no mecânico dele, [o mecânico aprovou]= }\end{array}$ & $\begin{array}{cc}4 & \text { REFU } \\
\text { EVI } & \text { LEGAL }\end{array}$ \\
\hline \begin{tabular}{|l|}
710 \\
711 \\
\end{tabular} & Ana & carro? cadê ela?= $\left[\begin{array}{llll}\text { e a:: : }- & \text { e a nota }] \text { fiscal do } \\
\end{array}\right.$ & - \\
\hline
\end{tabular}


EID\&A - Revista Eletrônica de Estudos Integrados em Discurso e Argumentação, Ilhéus, n. 15, jan./jun.2018.

\begin{tabular}{|c|c|c|c|}
\hline $\begin{array}{l}717 \\
718 \\
\end{array}$ & Ana & $\begin{array}{l}\text { tem que ter uma nota de venda, uê! (quer dizer } \\
\text { que) você é isento de- de pagar imposto? }\end{array}$ & - \\
\hline $\begin{array}{l}755 \\
756 \\
757 \\
758 \\
759\end{array}$ & Ana & $\begin{array}{l}\text { se você vendeu lá dentro do seu: } \text { do: }- \text { da- do- } \\
\text { da: : sua loja (0.8) no seu contrato social, está } \\
\text { como vendedor de carro, você vai me desculpar mas } \\
\text { você tem que dar uma nota fiscal. (6.0) o quê que } \\
\text { nós vamos fazer aí pra resolver isso é : : lucas? }\end{array}$ & 5 AMEAÇA \\
\hline 760 & & $(9.5)$ & - \\
\hline $\begin{array}{l}761 \\
762 \\
763 \\
\end{array}$ & Lucas & $\begin{array}{l}\text { deixa eu ver. oh! essa bomba aqui eu pago toda. } \\
\text { pronto, pra não ter conversa pra não ter-pra não } \\
\text { te::r-, essa bomba (elétrica). }\end{array}$ & \multirow[b]{2}{*}{6 ACEI } \\
\hline $\begin{array}{l}822 \\
823\end{array}$ & Lucas & $\begin{array}{l}\text { isso aqui eu vou arcar sozinho, [os duzentos e } \\
\text { cinquenta e um.] }\end{array}$ & \\
\hline $\begin{array}{l}830 \\
831 \\
832 \\
833 \\
\end{array}$ & Ana & 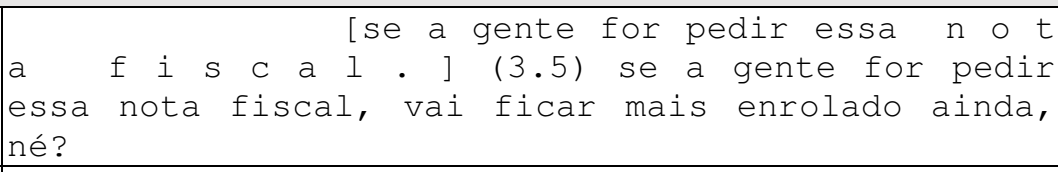 & 7 AMEAÇA \\
\hline 834 & & $(3.2)$ & - \\
\hline $\begin{array}{l}835 \\
836 \\
\end{array}$ & Lucas & $\begin{array}{l}\text { duzentos e cinquenta e um, é tudo que eu posso } \\
\text { pagar. }\end{array}$ & - \\
\hline 840 & José & NÃO: :, que isso- eu já [ gastei aqui ó: ] & - \\
\hline $\begin{array}{l}841 \\
842 \\
843\end{array}$ & Ana & \begin{tabular}{|crrr} 
& [senão, a gente] & encaminha isso pra \\
[justi:ça, encaminha & isso pra receita] &
\end{tabular} & \multirow[b]{2}{*}{8 AMEAÇA } \\
\hline $\begin{array}{l}849 \\
850 \\
851\end{array}$ & Ana & $\begin{array}{l}\text { então a gente encaminha isso pra justiça: }, \text { e pra } \\
\text { receita pra- pra: questionar sobre as not [ as } \\
\text { também. ] }\end{array}$ & \\
\hline $\begin{array}{lll}9 & 0 & 1 \\
9 & 0 & 2 \\
9 & 0 & 3 \\
\end{array}$ & José & $\begin{array}{l}\text { =não: : agora não quero bomba, não: : eu quero isso } \\
\text { aqui ó, quatrocentos e oitenta [e oito, cento e } \\
\text { dez] }\end{array}$ & 9 POSIN \\
\hline $\begin{array}{l}1222 \\
1223 \\
1224 \\
\end{array}$ & Lucas & $\begin{array}{l}\text { deixa eu te falar, eu vou então ( ) morrer a } \\
\text { nota, então. eu vou calcular um sensor desse aqui, } \\
\text { e eu vou te entregar um sensor. }\end{array}$ & $10 \mathrm{ACEI}$ \\
\hline 1276 & Ana & [você vai assumir os dois] $=$ & - \\
\hline 1277 & Lucas & =é ué. & - \\
\hline
\end{tabular}

O excerto (5) inicia-se com a retomada da posição associada de Lucas pela mediadora Marta. Esta relata à advogada do PROCON, Ana, que o reclamado alega que a garantia cobre apenas problemas no motor ou na caixa de marcha. No MA 2, Ana refuta esta posição com base em evidência legal - a garantia de noventa dias é prevista por lei.

Apesar disso, no MA 3, o reclamado refuta a mediadora, reafirmando sua posição associada. Desse modo, a mediadora no MA 4 reforça a refutação, 
EID\&A - Revista Eletrônica de Estudos Integrados em Discurso e Argumentação, llhéus, n. 15, jan./jun.2018.

acrescentando que, na lei, não há especificações do que é coberto ou não pela garantia, pois esta é integral.

Nos turnos seguintes, ao solicitar a nota fiscal da venda, Ana descobre que o documento não havia sido fornecido ao consumidor. Após alguns turnos discutindo se o reclamado possui ou não uma concessionária, se podia ou não vender carros em seu estabelecimento, que, na verdade, estava registrado como estacionamento, a mediadora se aproveita dessa situação para tentar um acordo entre as partes.

No MA 5, após responsabilizar o reclamado pela emissão da nota fiscal, Ana faz uma pergunta, "o quê que nós vamos fazer aí pra resolver isso é :: lucas?", que funciona como uma ameaça implícita, uma vez que a não emissão de nota fiscal pode ser entendida como sonegação de imposto, o que comprometeria Lucas junto à Receita Federal. Embora seja apresentada em forma de pergunta, é possível identificar a ameaça, denominada por Salgueiro (2010), condicional diretivo-comissiva, visto que o objetivo da mediadora não é denunciar o reclamado, mas sim convencê-lo a formular um acordo.

Cabe destacar que há uma pausa considerável (9.5) entre essa ameaça e o aceite de Lucas. Após vários turnos sustentando sua posição inicial de que não pagaria por nada que não fosse motor e caixa (POSAS), o reclamado finalmente propõe um acordo: pagar uma bomba elétrica no valor de duzentos e cinquenta e um reais, conforme MA 6 .

Ao perceber a eficácia de sua ameaça, Ana repete a estratégia no MA 7, porém de forma mais explícita. A mediadora verbaliza, de forma hipotética, a denúncia para a Receita Federal, após um período menor de pausa, Lucas reafirma que pode pagar apenas o que já se comprometeu.

Diante da recusa do reclamante em aceitar o acordo, a advogada recorre mais uma vez à ameaça no MA 8. Entretanto, a construção não é formulada como uma hipótese, mas sim como uma afirmação ("então a gente encaminha isso pra justiça::, e pra receita pra- pra: questionar sobre as not[ as também.]"). Apesar da força dessa estratégia, o reclamado apresenta-se irredutível em mudar de proposta e o reclamante em aceitá-la.

Após vários turnos de sequências não argumentativas, Lucas finalmente se compromete em orçar mais uma peça, um sensor, e arcar também com essa despesa. Ao final da audiência, o reclamado, que não queria pagar nada pelo conserto do carro, compromete-se com um terço das despesas. 
EID\&A - Revista Eletrônica de Estudos Integrados em Discurso e Argumentação, llhéus, n. 15, jan./jun.2018.

\section{Considerações finais}

Nosso estudo mostrou que, na audiência Ok Veículos, ocorre outro tipo de movimento argumentativo de sustentação, além dos identificados por Barletta (2014). A ameaça atua na argumentação como sustentação de uma posição. No caso, a mediadora, que defende o reclamante, usa a ameaça como estratégia argumentativa para convencer o reclamado a ressarcir o consumidor dos danos ocorridos com o carro, posição defendida pelo reclamante. É digno de nota que a mediadora somente produz a ameaça após os movimentos de sustentação e refutação das partes, isto é, depois de exauridas todas as possibilidades de construção do acordo, o que nos leva a crer que elas são apresentadas como último recurso argumentativo em um contexto institucional de conflito, tal como em audiências de conciliação no PROCON. Corroborando nossa hipótese, a análise preliminar de outras audiências do acervo mostra recorrência dessa estratégia na fase final de encontros, quando já se esgotaram todos os argumentos. Por outro lado, a ameaça é um movimento coconstruído, visto que a forma não se apresentou como elemento importante para a compreensão de uma ameaça.

Como destaca Salgueiro (2010), a ameaça é entendida como um ato prejudicial àquele que é ameaçado. No caso da audiência Ok veículos, o fato de ser encaminhado para a justiça poderia comprometer Lucas por sonegação de imposto, uma vez que não foi emitida nota fiscal da venda do carro. Desse modo, uma ameaça ser entendida ou não como argumento depende de como os participantes avaliam os danos de não realizar a ação pretendida pela ameaça.

Por fim, compreende-se que, dependendo do participante que realiza a ameaça, esta pode ter maior ou menor efeito. No contexto aqui investigado, a mediadora tem um papel institucional de controle da situação. Assim, pressupõe-se que uma ameaça realizada pela mediadora tenha maior força que aquela produzida por outro participante. Entretanto, são necessários trabalhos futuros que comprovem essa nossa intuição. 
EID\&A - Revista Eletrônica de Estudos Integrados em Discurso e Argumentação, llhéus, n. 15, jan./jun.2018.

\section{Referências}

ARISTÓTELES. Tópicos. Os pensadores. São Paulo: Abril, 1978.

AUSTIN, John Langshaw. How to do things with words. Oxford: Oxford University Press, 1962.

BARLETTA, Paula Luisa Silveira. Movimentos argumentativos em audiências de conciliação no PROCON. 2014. 151f. Dissertação (Mestrado em Linguística). Universidade Federal de Juiz de Fora/Faculdade de Letras.

CAPELLANI, Danielle Zuma. Estratégias argumentativas de posicionamento: a postura de não neutralidade em reportagens de capa de revistas de negócios. 2010. 18gf. Tese (Doutorado em Estudos da Linguagem). Pontifícia Universidade Católica do Rio de Janeiro/Faculdade de Letras.

DENZIN, Norman Kent; LINCOLN, Yvonna Sessions. Introduction: the discipline and practice of qualitative research. In: ZIN, Norman Kent; LINCOLN, Yvonna Sessions (Org.) The SAGE handbook of qualitative research. 3. ed. California: Sage, 2005.

DIAS, Nilza Barrozo; VIEIRA, Amitza Torres. A interface gramática e interação: cláusulas de finalidade e construções apositivas na sustentação de pontos de vista em uma audiência de conciliação do PROCON. In: SILVEIRA, Sonia Bittencourt; MAGALHÃES, Tânia Guedes (Org.). A fala-em-interação em situações de conflito: recursos linguísticos e práticas comunicativas. São Carlos, São Paulo: Claraluz, 2008. p. 133-149.

DIAS, Nilza Barrozo; VIEIRA, Amitza Torres. Argumentação e construção apositiva: uma proposta de interface. In: RODRIGUES, V. (Org.). Gramaticalização, combinação de cláusulas, conectores. 3 ed. Rio de Janeiro: Editora da UFRJ, 2012. p. 5-22.

GAGO, Paulo Cortês. Questões de transcrição em Análise da Conversa. Veredas, Juiz de Fora, v. 6, n. 2, p. 89-113, 2004.

GIL, Antônio Carlos. Métodos e técnicas de pesquisa social. São Paulo: Atlas, 1999.

GILLE, Johan. Pautas argumentativas en el diálogo espontáneo: un estudio de conversaciones intra e interculturales. 2001. 187 f. Tese (Doutorado em Linguística). Stockholm University/Department of Spanish and Portuguese.

GOFFMAN, Erving. Forms of Talk. Philadelphia: University of Pennsylvania Press, 1981.

MENEGUELLI, Gisella. Um estudo sobre elaboração e avaliação de material didático hipermodal para educação a distância. 2012. 146f. Dissertação (Mestrado em Linguística). Universidade Federal de Juiz de Fora/Faculdade de Letras.

SACKS, Harvey; SCHEGLOFF, Emanuel; JEFFERSON, Gail. A simplest systematics for the organization of turn taking for conversation. Language, v. 50, n. 4, p. 696-735, 1974. 
EID\&A - Revista Eletrônica de Estudos Integrados em Discurso e Argumentação, Ilhéus, n. 15, jan./jun.2018.

SALGUEIRO, Antonio Blanco. Promises, threats, and the foundations of Speech Act Theory. Disponível em: http://elanguage.net/journals/pragmatics/article/view/2569/2530. Acesso: jan. 2012.

SCHIFFRIN, Deborah. Discourse markers. Cambridge: Cambridge University Press, 1987. p. $13-21$.

SEARLE, John Rogers. Os actos de fala - um ensaio da filosofia da linguagem. Coimbra: Livraria Almedina, 1981.

SILVEIRA, Sonia Bittencourt; MAGALHÃES, Tânia Guedes (Org.). A fala-em-interação em situações de conflito: recursos lingüísticos e práticas comunicativas. São Carlos: Editora Claraluz, 2008.

VAN EEMEREN, F.H. Argumentation, communication, and fallacies: a pragmadialectical perspective. New Jersey: Lawrence Erlbaum, 1992.

VAN EEMEREN, Frans Hendrik; GROOTENDORST, Rob. Speech acts in argumentative discussions. Dordrecht: Foris Publications, 1984.

VIEIRA, Amitza Torres. A dimensão avaliativa da argumentação na fala opinativa de profissionais de uma empresa em processo de mudança. Tese (Doutorado em Letras/Estudos da Linguagem). 2007. 168 f. Pontifícia Universidade Católica do Rio de Janeiro/Faculdade de Letras.

VIEIRA, Amitza Torres. Movimentos argumentativos em uma entrevista televisiva: uma abordagem discursivo-interacional. Juiz de Fora: Clioedel, 2003. Disponível em: http://www.ufjf.br/clioedel/files/2009/10/COD03004.pdf. Acesso em: 02 jan. 2017. 
EID\&A - Revista Eletrônica de Estudos Integrados em Discurso e Argumentação, Ilhéus, n. 15, jan./jun.2018.

\section{Anexo 1. Convenções de transcrição}

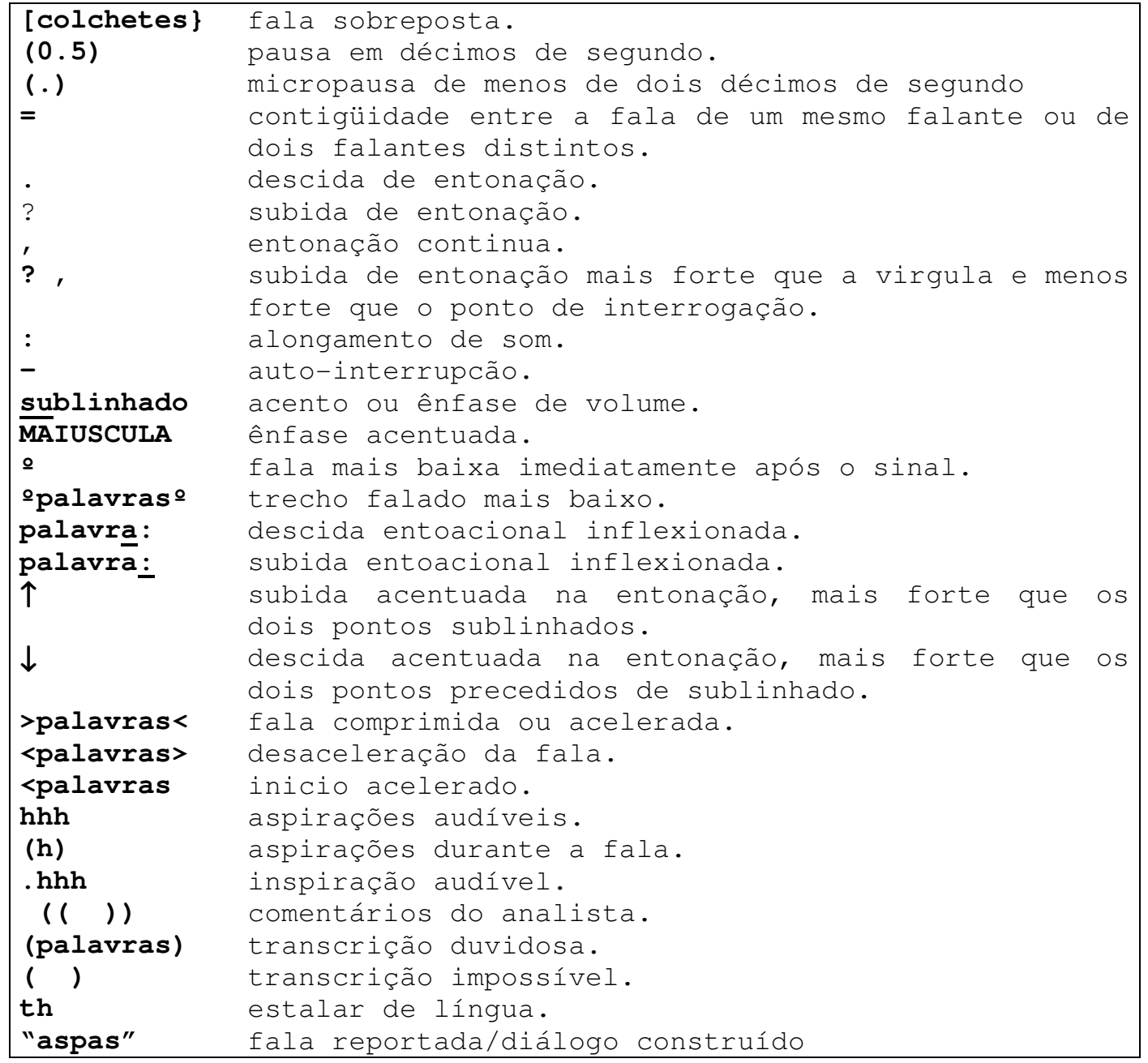

Forma de citação sugerida:

VIEIRA, Amitza Torres; SANTOS, Rogéria Tarocco dos. A ameaça como último recurso argumentativo em audiências de conciliação no PROCON. EID\&A - Revista Eletrônica de Estudos Integrados em Discurso e Argumentação, Ilhéus, n. 15, p. 1-23, jan./jun.2018. 